\title{
Lepidopterous Sex Attractants with a Conjugated Diene System
}

\author{
Tetsu Ando, Mizue KoIke, Masaaki Uchiyama \\ and Hiroshi KuroKo* \\ Department of Plant Protection, Faculty of Agriculture, \\ Tokyo University of Agriculture and Technology, \\ Fuchu, Tokyo 183, Japan \\ * Faculty of Agriculture, University of Osaka Prefecture, \\ Sakai 591, Japan \\ Received April 10, 1987
}

\begin{abstract}
Each.of fifty-one conjugated dienes (alcohols, acetates and aldehydes) with a $\mathrm{C}_{12}, \mathrm{C}_{14}$ or $\mathrm{C}_{16}$ straight chain was applied to a rubber cap in a sticky-type trap as a single-component lure. Some diene compounds were mixed with their functional derivatives or structurally related monoenes to make two-component lures. In field trials conducted from 1984 to 1986 , the new attraction of male moths of nineteen species was observed. These species were classified into nine families as follow: Gracillariidae, Yponomeutidae, Oecophoridae, Cosmopterigidae, Tortricidae (Olethreutinae and Tortricinae), Pyralidae, Pterophoridae, Drepanidae and Geometridae. This result indicates that the conjugated dienes are one of the main groups of lepidopterous sex pheromones. Some interesting information concerned with the taxonomy of the attracted moths and with the characteristics of the chemical structures of their attractants was obtained.
\end{abstract}

Many conjugated diene types of sex pheromones have been identified from female moths, ${ }^{1)}$ and field screening tests with synthetic pheromones and their analogues have successfully found new male attraction for a number of lepidopterous species. ${ }^{2)}$ These circumstances encouraged us to conduct systematic field tests with the conjugated diene compounds in order to get more information on the pheromones of species native to Japan. This paper deals with the preliminary result of a field test on about fifty dienes.

\section{MATERIALS AND METHODS}

Using the methods reported previously, ${ }^{3)}$ seventeen conjugated diene alcohols (nine dodecadien-1-ols: $(6 Z, 8 Z)$-, (6E,8Z)-, (7E,9Z)-, (8Z,10Z)-, (8Z,10E)-, (8E,10Z)-, $(8 E$, $10 E)-,(Z)-9,11$ - and $(E)-9,11$-isomers; five tetradecadien1-ols: $(8 E, 10 E)-,(9 Z, 11 E)-,(10 E, 12 E)-,(Z)-11,13-$ and $(E)-$ 11,13-isomers; and three hexadecadien-1-ols: $(10 E, 12 Z)$-, $(11 E, 13 Z)$ - and $(11 E, 13 E)$-isomers) and their derivatives (acetates and aldehydes) were synthesized. One $\mathrm{mg}$ of each of the fifty-one chemicals with more than $95 \%$ geo- metrical purity was applied to a rubber cap as a singlecomponent lure. Three groups of two-component lures (alcohol+acetate, acetate+aldehyde, and aldehyde+ alcohol) were made up by combinations of two compounds containing the same conjugated diene system, but with different functionalities. Thus, ten diene alcohols (seven dodecadien-1-ols: (7E,9Z)-, $(8 Z, 10 Z)-,(8 Z, 10 E)$-, (8E,10Z)-, $(8 E, 10 E)-,(Z)-9,11$ - and $(E)-9,11$-isomers; and three tetradecadien-1-ols: $(9 Z, 11 E)-,(Z)-11,13-$ and $(E)$ 11,13 -isomers) and their derivatives (acetates and aldehydes) were chosen as components. Two components were mixed in three different ratios $(9: 1,5: 5$ and $1: 9)$, and thirty lures were then prepared. Furthermore, some conjugated dienes were mixed with structurally related monoenes possessing same functionalities (also in ratios of $9: 1,5: 5$ and $1: 9)$ to make forty-five two-component lures as follow: $(8 E, 10 E)-8,10$-dodecadiene and $(E)-8$ dodecene compounds, $(Z)-9,11$-dodecadiene and (Z)-9dodecene compounds, $(E)$-9,11-dodecadiene and $(E)-9$ dodecene compounds, $(Z)$-11,13-tetradecadiene and $(Z)$ 11-tetradecene compounds, and $(E)$-11,13-tetradecadiene and $(E)$-11-tetradecene compounds. One mg of each twocomponent mixture was also applied to a rubber cap for evaluating its attractive activity. Each rubber cap was placed in a sticky-type trap, ${ }^{* 1}$ the field test being conducted from 1984 to 1986 in a forest located in the suburbs of Tokyo*2 in the same manner as that used for the

*1 The traps were kindly supplied by Shin-etsu Chemical Co.

*2 Asakawa Experimental Forest, Forestry and Forest Products Research Institute. 
screening tests of monoene compounds. ${ }^{4,5}$

\section{RESULTS AND DISCUSSION}

We have reported the sex attractants for about two hundred lepidopterous species which had been discovered by random screening tests with monoene compounds. ${ }^{4,5)}$ In this field trial, the new attraction of male moths of fifteen species to conjugated dienes and four species to mixtures of conjugated diene and monoene compounds was observed. These species had not been attracted to the lures consisting of only monoene compounds. The scientific names of the attracted moths, their attractants, time of their flight to the traps and the total number of attracted males are summarized in Table I. This result indicates that the conjugated dienes are one of the main groups of sex pheromones, and that a random screening test with synthetic dienes is useful for pheromone studies. The nineteen attracted

Table I. Sex Attractants Discovered by Field Tests of Conjugated Diene Compounds IN A FOREST IN TOKYO (HACHIOJI-SHI) FROM 1984 TO 1986

\begin{tabular}{|c|c|c|}
\hline $\begin{array}{l}\text { [Family] } \\
\text { Species }\end{array}$ & Attractant $^{a}$ & $\begin{array}{l}\text { Time of flight } \\
\text { (Number of attracted moths) }\end{array}$ \\
\hline \multicolumn{3}{|l|}{ [Gracillariidae] } \\
\hline Acrocercops sp. 1 & E8,E10-14: Ald & May (105) \\
\hline Acrocercops sp. 2 & E8,E10-14: Ald & June (123) \\
\hline Phyllonorycter pulchrum Kumata & $\mathrm{E} 8, \mathrm{E} 10-14: \mathrm{OAc}$ & May June $(80)$ \\
\hline \multicolumn{3}{|l|}{ [Yponomeutidae] } \\
\hline Xyrosaris lichneuta Meyrick & Z9,E11-14:OH & Apr. May (47) \\
\hline \multicolumn{3}{|l|}{ [Oecophoridae] } \\
\hline Acria ceramitis Meyrick & $\begin{array}{l}\mathrm{E} 8, \mathrm{Z} 10-12: \text { Ald }+\mathrm{E} 8, \mathrm{Z} 10-12: \mathrm{OAc} \\
\quad(5: 5)\end{array}$ & July (158), Sept. Oct. (337) \\
\hline \multicolumn{3}{|l|}{ [Cosmopterigidae] } \\
\hline Anatrachyntis sp. & E11,13-14: OAc & May June (1173), Aug. (231) \\
\hline \multicolumn{3}{|l|}{$\begin{array}{l}\text { [Tortricidae] } \\
\quad \text { (Olethreutinae) }\end{array}$} \\
\hline Aterpia issikii Kawabe & $\mathrm{Z} 8, \mathrm{Z} 10-12: \mathrm{OH}$ & May (28), Aug. (22) \\
\hline$\dot{H} e d y a$ dimidiana Clerck & $\mathrm{E} 8, \mathrm{E} 10-12: \mathrm{OAc}$ & May (23) \\
\hline Matsumuraeses falcana Walsingham ${ }^{6}$ & ${ }^{5} \mathrm{E} 8, \mathrm{E} 10-12: \mathrm{OAc}+\mathrm{E} 8-12: \mathrm{OAc}(5: 5)$ & Oct. $\sim$ Dec. $(148)$ \\
\hline Proschistis marmaropa Meyrick & $\mathrm{Z} 8, \mathrm{Z10}-12: \mathrm{OH}$ & Apr. $\sim$ May (41), Aug. $\sim$ Sept. (14) \\
\hline $\begin{array}{l}\text { Rhyacionia duplana simulata } \\
\cdot \text { Heinrich } \\
\text { (Tortricinae) }\end{array}$ & Z8,E10-12:OAc & Apr. (49) \\
\hline Acleris affinitana Snellen & E11,13-14: Ald & Apr. May (55) \\
\hline Acleris hispidana Christoph & E11,13-14:Ald + E11-14:Ald $(5: 5)$ & Apr. May (14) \\
\hline Acleris japonica Walsingham & E11,13-14: Ald + E11-14: Ald $(9: 1)$ & Apr. May (39), July Aug. (58) \\
\hline Acleris nigrilineana Kawabe & E11,13-14:Ald +E11-14: Ald $(5: 5)$ & Apr. May (21) \\
\hline \multicolumn{3}{|l|}{ [Pyralidae] } \\
\hline Tequlifera bicoloralis Leech & E11,13-14:Ald + E11-14: Ald $(9: 1)$ & July (37) \\
\hline \multicolumn{3}{|l|}{ [Pterophoridae] } \\
\hline Pselnophorus vilis Butler & $\begin{array}{l}\text { Z9,E11-14: Ald + Z9,E11-14: OAc } \\
\quad(9: 1)\end{array}$ & June $\sim$ Sept. (26) \\
\hline \multicolumn{3}{|l|}{ [Drepanidae] } \\
\hline \multicolumn{3}{|l|}{ [Geometridae] } \\
\hline Idaea biselata Hufnagel & E7,Z9-12:OAc +E7,Z9-12: Ald (5:5) & Oct. (12) \\
\hline Idaea trisetata Prout & E7,Z9-12:OH & July (12), Sept. (44) \\
\hline
\end{tabular}

a The chemical formulae are symbolized by $Z=(Z)$-isomer, $\mathrm{E}=(E)$-isomer, the number before the hyphen giving the position of unsaturation, the number after the hyphen giving the carbon atoms in the chain, $\mathrm{OH}=$ alcohol, $\mathrm{OAc}=$ acetate, and $\mathrm{Ald}=$ aldehyde. 
species were divided into nine families as follow: Gracillariidae (three species), Yponomeutidae (one species), Oecophoridae (one species), Cosmopterigidae (one species), Tortricidae (Olethreutinae, four species; Tortricinae, four species), Pyralidae (one species), Pterophoridae (one species), Drepanidae (one species), and Geometridae (two species). No species in the family Drepanidae have been attracted before in Japan, while monoene attractants for the eight other families were found in our previous tests. ${ }^{4,5)}$

Compounds with a 8,10-dodecadiene system have been reported as pheromone components for some species in the sub-family Olethreutinae of the family Tortricidae. ${ }^{1)}$ In this field test, the new attraction to 8,10-dodecadienes of four Olethreutinae species (Aterpia issikii, Hedya dimidiana, Proschistis marmaropa and Rhyacionia duplana simulata) was revealed, in addition to Matsumuraeses falcana, the sex pheromone of which was recently found to be a mixture of $(8 E, 10 E)$-8, 10 -dodecadienyl acetate and $(E)$-8-dodecenyl acetate. ${ }^{6)}$ It is supported by this result that 8,10-dodecadienes are one of the characteristic components in the pheromones of the Olethreutinae species, while Acria ceramitis in the family Oecophoridae, which taxonomically unrelated to Olethreutinae, was interestingly attracted by the 8,10 -dodecadiene.

On the other hand four species in the subfamily Tortricinae of Tortricidae (Acleris affnitana, A. hispidana, A. japonica and A. nigrilineana) were attracted by $(E)-11,13$ tetradecadienal or its mixture with $(E)-11$ tetradecenal. Currently, there is no literature reporting 11,13-tetradecadienes, but compounds with a 11-tetradecene system have been identified from the pheromone glands of as many as twenty-six Tortricinae species. ${ }^{1)}$ Several mixtures of monoene and diene compounds are known to be two-component lepidopterous pheromones. One double bond of the diene component is always located at the same position as the monoenes. ${ }^{1)}$ Since the 11,13-diene is considered as such a derivative of the 11-monoene, the 11,13-diene might be one of the key pheromone components for Tortricinae species, especially the genus Acleris. The 11,13-dienes also attracted the Cosmopterigidae and Pyralidae species (Anatrachyntis sp. and Tequlifera bicoloralis) as the 11-monoenes attracted some other species in these two families in past field tests. ${ }^{4,5}$ )

Although $(9 Z, 11 E)-9,11$-tetradecadienyl acetate is known to be a pheromone component of Noctuidae females, ${ }^{1)}$ no Noctuidae species but three species in other families were caught by the 9,11-diene and its functional derivatives. Namely, Xyrosaris lichneuta in Yponomeutidae, Pselnophorus vilis in Pterophoridae and Macrauzata maxima in Drepanidae were attracted to the lures baited with $(9 Z, 11 E)-9,11-$ tetradecadien-1-ol, the mixture of its aldehyde and acetate derivatives, and the aldehyde derivative, respectively. In Canada, the diene and $(9 Z, 11 Z)$-geometrical isomers have attracted male moths in two families (Drepanidae and Geometridae). ${ }^{2)}$ So the 9,11-diene system might be included in the pheromone components of several families without indicating the taxonomical character of the species. It is noteworthy that the $(9 E, 11 E)$-geometrical isomer of the diene acetate has been isolated from one Tortricidae species. ${ }^{7)}$

We observed the attraction of three Gracillariidae species to $(8 E, 10 E)-8,10$-tetradecadienes, Phyllonorycter pulchrum being attracted to the diene acetate, and two Acrocercops species, to the diene aldehyde. Traps baited with the 8,10-dienes have also caught one Gracillariidae species in Canada. ${ }^{2}$ In our past test, $(Z)$-10-tetradecenyl acetate, a structurally related compound of the 8,10-tetradecadienes, attracted one Gracillariidae species. ${ }^{4)}$ These findings indicate that the 8,10 dienes might be characteristic components of the Gracillariidae pheromones, while no 8,10tetradecadienes have been identified from female moths yet.

7,9-Dodecadienyl acetate, identified from only Olethreutinae species, has been reported as an attractant of not only Olethreutinae, ${ }^{2)}$ but also of Geometridae species. ${ }^{8)}$ In our ex- 
periment, two Geometridae species were also captured by the compounds with the 7,9dodecadiene system.

We finished the field evaluation of synthetic lures with five other diene systems. Some compounds with a 9,11-dodecadiene, 10,12-tetradecadiene, 10,12-hexadecadiene or 11,13-hexadecadiene system are the components of lepidopterous pheromones, ${ }^{1)}$ but this time they did not effect their activities on any species contrary to our expectation. 6,8-Dodecadienes also did not attract any male moths. No components with this diene system have been identified before as lepidopterous pheromones, and this is the first time for their field evaluation. There are many conjugated dienes considered as candidates for sex pheromones, because of four geometries and many variations of the double bond position. The dienes used in this test were very limited, and in the future, it will be necessary to examine diene compounds more systematically in many different environments.

\section{REFERENCES}

1) Y. Tamaki, "Comprehensive Insect Physiology, Biochemistry and Pharmacology," Vol. 9, Behavior, ed. by G. A. Kerkut and L. I. Gilvert, Pergamon Press, New York, 1985, pp. 145 191.

2) D. W. Reed and M. D. Chisholm, J. Chem. Ecol., 11, 1645 (1985), and other references cited therein.

3) T. Ando, Y. Kurotsu, M. Kaiya and M. Uchiyama, Agric. Biol. Chem., 49, 141 (1985).

4) T. Ando, S. Yoshida, S. Tatsuki and N. Takahashi, Agric. Biol. Chem., 41, 1485 (1977).

5) T. Ando, H. Kuroko, S. Nakagaki, O. Saito, T. Oku and N. Takahashi, Agric. Biol. Chem., 45, 487 (1981).

6) S. Wakamura, Appl. Entomol. Zool., 20, 189 (1985).

7) T. E. Bellas, R. J. Bartell and A. Hill, J. Chem. Ecol., 9, 503 (1983).

8) G. Biwer, B. Lalanne-Cassou, C. Descoins and D. Samain, C. R. Acad. Sci. Paris, 280(D), 1469 (1975). 